\title{
BMJ Open Systematic analysis of funding awarded for mycology research to institutions in the UK, 1997-2010
}

\author{
Michael G Head, ${ }^{1}$ Joseph R Fitchett, ${ }^{2}$ Rifat Atun, ${ }^{3,4}$ Robin C May ${ }^{5}$
}

To cite: Head MG, Fitchett JR, Atun R, et al. Systematic analysis of funding awarded for mycology research to institutions in the UK, 19972010. BMJ Open 2014;4: e004129. doi:10.1136/ bmjopen-2013-004129

- Prepublication history for this paper is available online. To view these files please visit the journal online (http://dx.doi.org/10.1136/ bmjopen-2013-004129).

Received 27 September 2013 Revised 14 November 2013 Accepted 15 November 2013

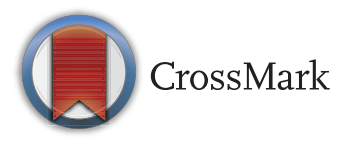

\footnotetext{
${ }^{1}$ Research Department of Infection and Population Health, University College London, London, UK ${ }^{2}$ Department for Infectious Diseases, King's College London, London, UK ${ }^{3}$ Imperial College London, London, UK

${ }^{4}$ Harvard School of Public Health, Harvard University, Boston, Massachusetts, USA ${ }^{5}$ Institute of Microbiology \& Infection and School of Biosciences, University of Birmingham, Birmingham, UK
}

Correspondence to Michael G Head;

m.head@ucl.ac.uk

\begin{abstract}
Objectives: Fungal infections cause significant global morbidity and mortality. We have previously described the UK investments in global infectious disease research, and here our objective is to describe the investments awarded to UK institutions for mycology research and outline potential funding gaps in the UK portfolio.
\end{abstract}

Design: Systematic analysis.

Setting: UK institutions carrying out infectious disease research.

Primary and secondary outcome measures:

Primary outcome is the amount of funding and number of studies related to mycology research. Secondary outcomes are describing the investments made to specific fungal pathogens and diseases, and also the type of science along the R\&D value chain.

Methods: We systematically searched databases and websites for information on research studies from public and philanthropic funding institutions awarded between 1997 and 2010, and highlighted the mycology-related projects.

Results: Of 6165 funded studies, we identified 171 studies related to mycology (total investment $£ 48.4$ million, $1.9 \%$ of all infection research, with mean annual funding $£ 3.5$ million). Studies related to global health represented $5.1 \%$ of this funding (£2.4 million, compared with $35.6 \%$ of all infectious diseases). Leading funders were the Biotechnology and Biological Sciences Research Council ( $£ 14.8$ million, 30.5\%) and Wellcome Trust ( $£ 12.0$ million, $24.7 \%$ ). Preclinical studies received $£ 42.2$ million $(87.3 \%)$, with clinical trials, intervention studies and implementation research in total receiving $£ 6.2$ million (12.7\%). By institution, University of Aberdeen received most funding ( $£ 16.9$ million, $35 \%$ ). Studies investigating antifungal resistance received £1.5 million (3.2\%).

Conclusions: There is little translation of preclinical research into clinical trials or implementation research in spite of substantial disease burden globally, and there are few UK institutions that carry out significant quantities of mycology research of any type. In the context of global health and the burden of disease in lowincome countries, more investment is required for mycology research.

\section{Strengths and limitations of this study}

- This is the first study to present detailed systematically collected data and rigorously quantify funding related to mycology research investments made to UK institutions.

- Our results highlight clear gaps in the UK research portfolio and illustrate some priority areas for funders and policymakers.

- We also highlight strengths in preclinical research in the UK.

- We do not have private sector data, and their contributions to areas such as diagnostics and vaccine development are currently unknown. Further international data is required to assess the true research gaps related to global mycology investments.

- Categorising is subjective, and we do not take into account funding of overheads or the impact of the introduction of full economic costing.

\section{INTRODUCTION}

Fungal pathogens account for significant burden of human disease globally. Prevalence of serious fungal infection in Brazil is estimated at $1.7 \%$ of the population, $1.9 \%$ in Ireland and the burden of fungal disease in China is thought to be among the greatest in the world. ${ }^{1}$ Cryptococcal meningitis has been estimated to cause over 600000 deaths globally per annum, with a comparable mortality rate to tuberculosis in sub-Saharan Africa. $^{2}$ Aspergillosis and Candidiasis have relatively high mortality rates and cause in excess of 200000 and 400000 life-threatening infections each year. ${ }^{3}$ Incidence of coccidiomycosis has increased sharply in recent years. ${ }^{4}$ However, estimates can widely vary, as the WHO has no programme on fungal infection, and most public health agencies, apart from the US Centers for Disease Control and Prevention, conduct little or no mycological surveillance. ${ }^{3}$ Mycology infections also have a role to play in allergic and inflammatory diseases. 56 
There are some treatment options available for fungal disease, ${ }^{7}$ with relatively low levels of resistance to currently available medicines, but very few options for prevention-there are no existing vaccines. The majority of the burden appears to be in low-income and middle-income countries-countries with weak health systems, and thus suitable diagnostics and distribution of treatments may be lacking. In high-income countries, it is immunosuppressed individuals who are particularly vulnerable to invasive fungal disease. ${ }^{7}$

UK research institutions received at least £2.6 billion of public and philanthropic funding to carry out infectious disease research between 1997 and 2010 from a variety of national and international funding sources. ${ }^{8}$ This funding was spent on all types of science along the research pipeline, from preclinical studies to clinical trials and implementation research. However, there appear to be relatively few UK research centres with a focus on mycology research. We report here the research funding that was awarded to UK institutions specifically for mycology-related research, along with temporal trends and the relative proportions allocated. We assess how closely the topics funded relate to the clinical and public health burden of mycology disease, seeking to identify potential funding gaps that policymakers and funders can be encouraged to focus on in future, and areas where the UK has clear research strengths.

\section{METHODS}

The analyses in this article focused on studies funded in a 14-year period (1997-2010 inclusive) that were relevant to, or had specific mention of, fungal pathogens. The methods have been described in detail elsewhere, ${ }^{8}$ but are reiterated briefly here. The overarching dataset was obtained from several sources of public and charitable funding for infectious disease research studies, including the Wellcome Trust, Medical Research Council and other research councils, UK government departments, European Commission, Bill and Melinda Gates Foundation and other research charities. Data collection was via (1) downloading all data from the funder website and manually filtering the infectious disease studies; or (2) searching open access databases on the funder website for infection-related keyword terms or (3) contacting the funder directly and requesting details of their infection studies. Funders were identified through author's knowledge of the R\&D landscape and searches on the Internet. The majority of data extraction was performed by author $\mathrm{MGH}$, with support from author JRF and other colleagues. Each study was assigned to as many primary disease categories as appropriate. ${ }^{9}$ Within each category, topic-specific subsections (including specific pathogen or disease) were documented. Global health studies were defined as those where the study had a clear reference to another country (eg, cryptococcal meningitis in South Africa). Studies were also allocated to one of four R\&D categories: preclinical; phase 1, 2 or 3; product development; and implementation and operational research (including surveillance, epidemiology and statistical and modelling projects). Funders were either considered in their own right, or for convenience, some were grouped into categories such as research charities and government departments. We used 26 funder categories. ${ }^{9}$ No private sector funding was included in this analysis as the publicly available data from these sources were very limited and considered to be under-representative. Studies were excluded if (1) they were not immediately relevant to infection; (2) they were veterinary infectious disease research studies with no clear implications for zoonoses; (3) they concerned the use of viral vectors to investigate non-communicable diseases; (4) they were grants for symposia or meetings or (5) they included UK researchers, but with the funding awarded to and administered through a non-UK institution. Unfunded studies were also excluded. Grants awarded in a currency other than pounds sterling were converted into UK pounds using the mean exchange rate in the year of the award. All awards were adjusted for inflation and reported in 2010 UK pounds. Data management was carried out in Microsoft Excel and Access (versions 2000 and 2007) and statistical analysis in Stata (V.11).

\section{RESULTS}

We identified 6165 studies funded within the 14-year period and covering all infectious disease research representing a total investment of $£ 2.6$ billion. Investments for mycology research were $£ 48.4$ million across 171 studies (1.9 and 2.8\% of total funding and study numbers, respectively). Mean annual funding was $£ 3.5$ million, ranging from $£ 0.7$ million in 1998 to $£ 10.4$ million in 2008.

By pathogen, Candida received the greatest investment (£22.8 million, 76 studies) followed by Aspergillus ( $£ 4.8$ million, 26 studies), with fewer studies relating to cryptococcosis (9 studies, £3.5 million) and Paracoccidioides (4 studies, all awarded over 10 years ago, £462 478; tables 1 and 2). Median funding per mycology project was $£ 138257$ (IQR £41 162-338 222), and the mean was $£ 238067$ (SD $£ 447190$ ). There was no clear temporal trend (figure 1A). By type of science along the R\&D value chain, $£ 42.2$ million $(87 \%)$ was directed towards preclinical research, and £2.6 million $(5 \%)$ towards implementation and operational research. The remaining investments were for either phases I-IV trials or product development studies (figure 1B, tables 1 and 2).

There were nine studies with a clear focus on global health, totalling £2.5 million. There were also four studies on paediatric mycology infection ( $£ 0.1$ million), five related to coinfection with HIV (£2.8 million), 27 related to therapeutics ( $£ 4.5$ million) and 14 studies on antimicrobial resistance ( $£ 1.5$ million). There were five studies classified as related to dermatological fungal 
i-

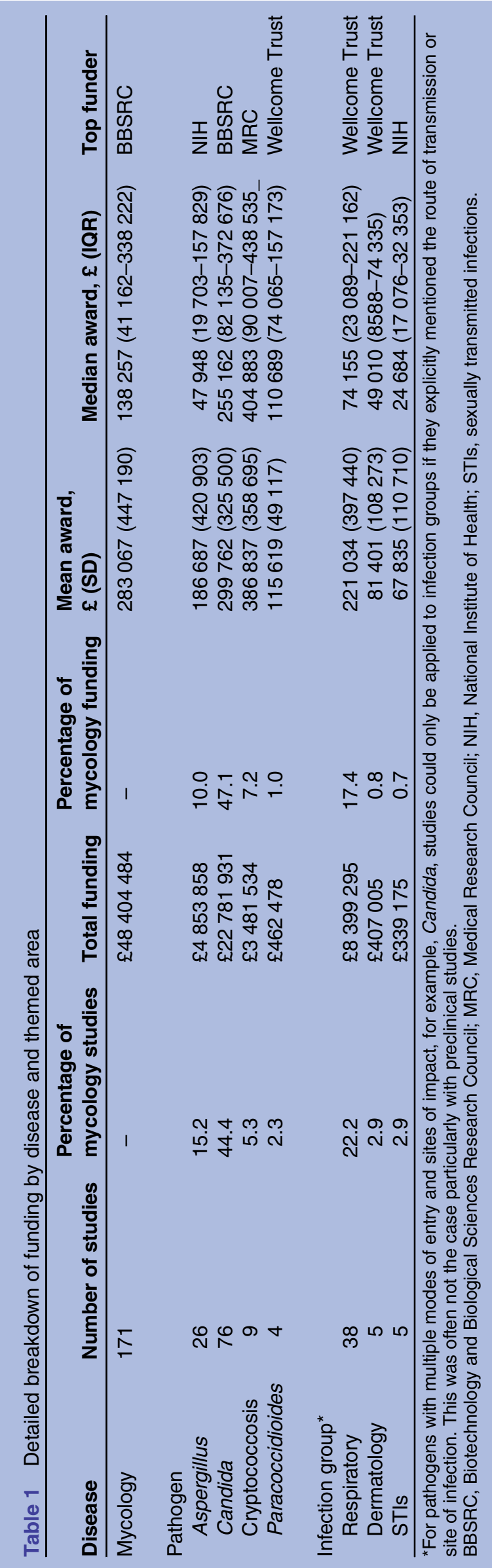

nfection, totalling £0.4 million. Four studies considered fungal pathogens in the context of healthcare-associated infections. There were no studies looking at mycology and vaccinology.

The greatest total investment was awarded by the Biotechnology and Biological Sciences Research Council (BBSRC), with 36 awards totalling $£ 14.8$ million, followed by the Wellcome Trust (£12.0 million, 49 studies). University of Aberdeen was awarded £17.0 million $(35 \%)$, and Imperial College London $£ 4.5$ million $(9.4 \%)$.

\section{DISCUSSION}

The UK has received investments from public and philanthropic funding sources totalling at least $£ 48.4$ million across 171 studies during the 14-year time period of this study, and this is approximately $2 \%$ of total investments related to all infectious disease. This figure is comparable to estimates made elsewhere. ${ }^{7}$ The vast majority of investments are in preclinical research, and the BBSRC and the Wellcome Trust provided the majority of funding. Candida is the most studied pathogen. The University of Aberdeen is clearly the leading UK institution for mycology research, receiving over one-third of the total investments.

There is very little mycology research that has a specific focus on global health (£2.5 million, $5.1 \%$ ). This is an unexpected finding, given that across all infectious diseases $35.6 \%$ of funding had a clear global health component. ${ }^{8}$ The lower investment may be a result of almost all of the research being preclinical, and thus hard to attribute to a global health category (most of the global health research in the larger study is translational in nature). This general lack of translation of research along the research pipeline from the preclinical stage through to more translational components is something for policymakers and funders to focus on in the short-term and medium-term future.

The lack of high-quality routine data, diagnostics, and that many fungal pathogens are commonly only found in resource-poor settings, may also contribute to this apparent lack of global health research. The few investments, for example, related to Paracoccidioides are all from over 10 years ago. There are no clear research investments in vaccinology and mycology disease in our dataset, but several studies relate to therapeutics. Antimicrobial resistance is not currently considered too severe (relative to areas such as many Gram-negative pathogens or tuberculosis) as there are efficacious treatment options for treating fungal pathogens. However, there are sometimes limited options available and drug interactions and toxicity can be problematic, and prevalence of resistance in Candida ${ }^{10}$ and Aspergillus ${ }^{11}$ is increasing. Thus, it is surely prescient to assess the likely future burden of resistance to antifungal drugs now, rather than waiting for the problems to emerge, particularly considering the historic underinvestment in 
Table 2 Detailed breakdown of funding by disease, themed area and corresponding type of science along the R\&D value chain

\begin{tabular}{|c|c|c|c|c|c|c|c|c|}
\hline \multirow[b]{2}{*}{ Disease } & \multicolumn{2}{|c|}{ Preclinical } & \multicolumn{2}{|c|}{ Phases I-III } & \multicolumn{2}{|c|}{ Product development } & \multicolumn{2}{|c|}{ Operational } \\
\hline & $\begin{array}{l}\text { Study } \\
\text { numbers }\end{array}$ & Funding & $\begin{array}{l}\text { Study } \\
\text { numbers }\end{array}$ & Funding & $\begin{array}{l}\text { Study } \\
\text { numbers }\end{array}$ & Funding & $\begin{array}{l}\text { Study } \\
\text { numbers }\end{array}$ & Funding \\
\hline Mycology & 125 & $£ 42244247$ & 5 & $£ 2008147$ & 11 & $£ 1536372$ & 30 & $£ 2615719$ \\
\hline \multicolumn{9}{|l|}{ Pathogen } \\
\hline Aspergillus & 20 & $£ 4526214$ & 1 & $£ 6721$ & 0 & $£ 0$ & 5 & $£ 320923$ \\
\hline Candida & 70 & $£ 21598686$ & 0 & $£ 0$ & 0 & $£ 0$ & 6 & $£ 1183245$ \\
\hline Cryptococcosis & 5 & $£ 1668260$ & 1 & $£ 1234684$ & 3 & $£ 578591$ & 0 & $£ 0$ \\
\hline Paracoccidioides & 4 & $£ 462478$ & 0 & $£ 0$ & 0 & $£ 0$ & 0 & $£ 0$ \\
\hline \multicolumn{9}{|l|}{ Infection group* } \\
\hline Respiratory & 26 & $£ 5620674$ & 3 & $£ 1789554$ & 3 & $£ 578591$ & 6 & $£ 410477$ \\
\hline Dermatology & 2 & $£ 342617$ & 0 & $£ 0$ & 1 & $£ 8588$ & 2 & $£ 55801$ \\
\hline STIS & 3 & $£ 297416$ & 0 & $£ 0$ & 0 & $£ 0$ & 2 & $£ 41760$ \\
\hline
\end{tabular}

antimicrobial resistance generally. ${ }^{12}$ There appears to be almost no investment on studies that specifically looked at fungal infections and coinfection with HIV-given the severity of the rising burden in this area, it would seem to be another important area for increased focus. Briefly assessing the global numbers of estimated deaths and life-threatening infections, perhaps cryptococcal disease is relatively the most underfunded fungal disease, for example, as compared with Aspergillus and Candida infection (though they all of course warrant increased investment). Nosocomial infections were also neglected, with just four studies specifically investigating this area and none of them focusing on Candida or Aspergillus infection. The complete absence of any public or philanthropic funding for vaccine research is concerning, and though therapeutics were the subject of 27 studies, they often received only small amounts of investment.

The University of Aberdeen clearly leads on receiving investments for human mycology research. Other institutions are some way behind in terms of total funding received, and given the relatively small sums of funding involved, just one or two principal investigators transferring institutions can easily impact on which universities will receive future investments. Our analysis does not document investments awarded to international institutions where there was a UK collaborator receiving funds, and this does highlight the need for international databases of mycology research funding that can draw together such collaborations, and whether other countries are filling apparent gaps in the UK research portfolio.

Our study has several limitations, which have been highlighted and discussed in detail elsewhere. ${ }^{8}$ There was little publicly available data from the pharmaceutical industry. Hence, there is a data gap in relation to funding of clinical trials and development of vaccines and diagnostics, which the pharmaceutical and biotechnology industries are financing. We rely on the original data being complete and accurate, and are unable to take into account distribution of funds from the lead institution to collaborating partners, nor can we assess quantity of each award given to overheads or the impact of the introduction of full economic costing. Also, assigning studies to categories is a subjective and imperfect process-although we used two researchers when assigning finding to categories to reduce interobserver error.

This is the first national systematic analysis of all infectious disease research investments. There are no other national databases of systematically collected research funding, so comparisons with the mycology research investments of other countries are not possible. Thus, there is a need for similar analyses across the European Union, the USA and other countries, to allow for construction of a global database of mycology research projects, which will allow highlighting of existing expertise, technology and outputs, and help to promote international collaboration in areas of high need and reduce duplication of research.

\section{CONCLUSIONS}

The UK has clear strengths in preclinical mycology research, but there is little investment in more translational projects further down the $\mathrm{R} \& \mathrm{D}$ value chain, and funders and policymakers should seek to address this. There are also gaps in some of the neglected highburden mycological infections such as Cryptococcus. Improved global surveillance and data collection for all fungal pathogens will help in targeting research funds towards the most appropriate and impactful proposals. 
Figure 1 (A) Total investment for mycology research over time, by type of science along the $R \& D$ value chain. (B) Proportion of investment in mycology research over time, by type of science along the $R \& D$ value chain.

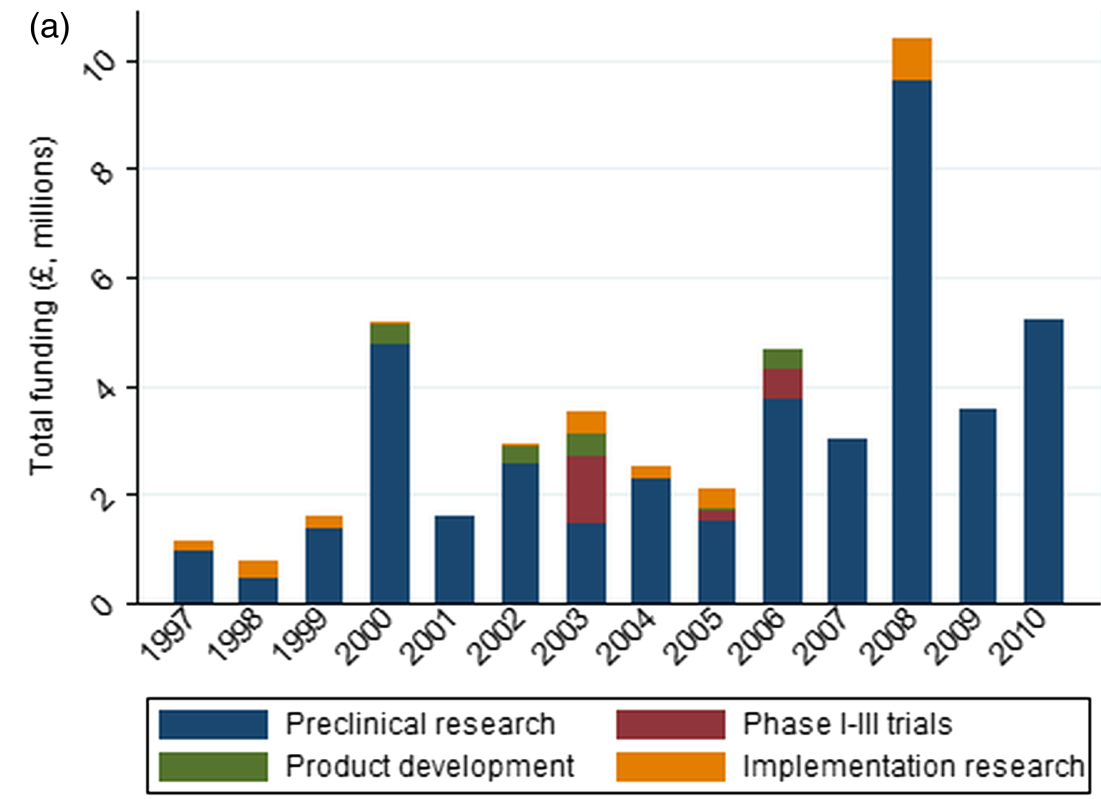

(b)

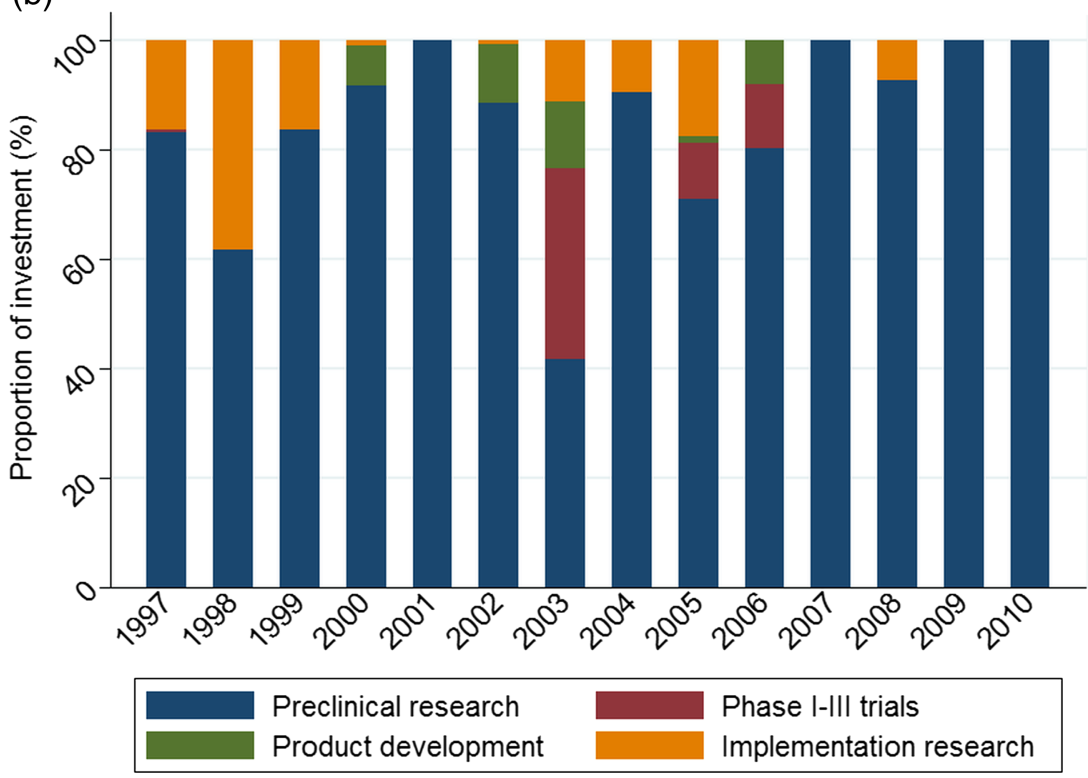

Resistance to antifungal drugs is not yet as urgent a priority as for bacterial infections, but there must be proactivity in addressing the likely future resistance burden. Epidemiological and economic studies will help more accurately quantify the health and financial burden of fungal infections, and partnerships with the private sector are urgently needed to introduce vaccines and new diagnostics that can be implemented in resourcepoor settings. In the short term, investments in operational research, for how best to distribute existing effective treatments to areas of high need, would be useful.

Funders based in other countries should also be encouraged to release their funding data for similar systematic analyses, to allow for construction of a global database of previous and current mycology research projects. Improved surveillance systems and national surveys to collect more rigorous data on incidence and prevalence of fungal infections would be useful in allowing comparisons of investments in research with the health and economic burden of mycological disease.

Acknowledgements The authors would like to thank the Infectious Disease Research Network for their input and support, and also the funding agencies that have supported this study and provided data.

Contributors MGH designed the study with input from RA and JRF and collated the dataset. JRF and RCM checked and refined the dataset. MGH undertook data analysis and created the graphs and figures with input from JRF. MGH interpreted the data and wrote the first draft. MGH, JRF, RA and RCM refined the analysis and the manuscript. All the authors reviewed and approved the final version. MGH is guarantor of the article.

Funding This research received no specific grant from any funding agency in the public, commercial or not-for-profit sectors.

Competing interests RA has received research funding from the UK Medical Research Council, the UK National Institute for Health Research, UK CRC, UK 
EPSRC, the UK Department for International Development and the UK Department of Health. RA is a member of the UK Medical Research Council Global Health Group. MGH works for the Infectious Disease Research Network (IDRN), which has supported this work and is funded by the UK Department of Health. JRF has received funds from the Wellcome Trust and is a steering group member for the IDRN. RCM is a steering group member for the IDRN and is funded by the UK Medical Research Council, the Wellcome Trust, the National Institutes of Health Surgical Reconstruction and Microbiology Research Centre and the Lister Institute for Preventive Medicine.

Provenance and peer review Not commissioned; externally peer reviewed.

Data sharing statement Further data relating to the Research Investments project can be found at http://www.researchinvestments.org or by contacting the corresponding author.

Open Access This is an Open Access article distributed in accordance with the Creative Commons Attribution Non Commercial (CC BY-NC 3.0) license, which permits others to distribute, remix, adapt, build upon this work noncommercially, and license their derivative works on different terms, provided the original work is properly cited and the use is non-commercial. See: http:// creativecommons.org/licenses/by-nc/3.0/

\section{REFERENCES}

1. Leading International Fungal Education. Burden of fungal infection abstracts. In: 12th European Congress on Clinical Microbiology and Infectious Diseases. Berlin, 2013. http://www.life-worldwide.org/assets/ uploads/files/ECCMID global Burden abstracts final Nov 2012 3.pdf
2. Park BJ, Wannemuehler KA, Marston BJ, et al. Estimation of the current global burden of cryptococcal meningitis among persons living with HIV/AIDS. AIDS 2009;23:525-30.

3. Brown GD, Denning DW, Gow NAR, et al. Hidden killers: human fungal infections. Sci Transl Med 2012;4:165rv13.

4. Brown J, Benedict K, Park BJ, et al. Coccidioidomycosis: epidemiology. Clin Epidemiol 2013;5:185-97.

5. Ghosh S, Hoselton SA, Dorsam GP, et al. Eosinophils in fungus-associated allergic pulmonary disease. Front Pharmacol 2013;4:8.

6. Pakdaman MN, Corry DB, Luong A. Fungi linking the pathophysiology of chronic rhinosinusitis with nasal polyps and allergic asthma. Immunol Invest 2011;40:767-85.

7. Brown GD, Denning DW, Levitz SM. Tackling human fungal infections. Science 2012;336:647.

8. Head MG, Fitchett JR, Cooke MK, et al. UK investments in global infectious disease research 1997-2010: a case study. Lancet Infect Dis 2012. http://www.ncbi.nlm.nih.gov/pubmed/23140942 (accessed 17 Nov 2012).

9. Researchlnvestments.org. http://www.researchinvestments.org/ (accessed 30 May 2012).

10. Iñigo M, Pemán J, Del Pozo JL. Antifungal activity against Candida biofilms. Int J Artif Organs 2012;35:780-91.

11. Vermeulen E, Cooreman S, Maertens J, et al. Azole resistance in Aspergillus: an emerging problem? Acta Clin Belg 2012;67: 322-7.

12. Head MG, Fitchett JR, Cooke MK, et al. Systematic analysis of funding awarded for antimicrobial resistance research to institutions in the UK, 1997-2010. J Antimicrob Chemother 2013. http://www.ncbi.nlm.nih.gov/pubmed/24038777 (accessed 26 Sep 2013). 